\title{
The use of hysteroscopic metroplasty with diode laser to increase endometrial volume in women with septate uterus: preliminary results
}

\author{
Luigi Nappi ${ }^{1}$, Maddalena Falagario ${ }^{1}$, Stefano Angioni ${ }^{2}$, Vincenzo De Feo ${ }^{1}$, Michele Bollino ${ }^{1}$ and \\ Felice Sorrentino ${ }^{1 *}$ (i)
}

\begin{abstract}
Background: Septate uterus is a common Mullerian ducts anomaly. The aim of our pilot study was the evaluation of diode laser hysteroscopic metroplasty efficacy to increase endometrial volume in women with septate uterus.

Results: We prospectively enrolled 10 consecutive patients with septate uterus undergoing office hysteroscopic metroplasty with diode laser between February and November 2019. Endometrial volume was evaluated before and 3 months after surgery using 3D transvaginal ultrasound. The surgical procedure was uncomplicated in all patients, the endometrial volume increased at 3 months follow-up (the median increase was $1.9 \mathrm{~cm}^{3}$ (range 1.72.1), and there was a complete removal of septum with no intrauterine synechiae at follow-up hysteroscopy.

Conclusions: Office hysteroscopic metroplasty with diode laser is a safe procedure and has preliminary showed to increase endometrial volume. The increase in endometrial volume by 3D-TV US could be used as a prognostic factor for the reproductive outcomes.
\end{abstract}

Keywords: Septate uterus, Metroplasty, Diode laser, Hysteroscopy, 3D ultrasound

\section{Background}

Mullerian ducts anomalies (MDA) stem from a defect in Mullerian ducts fusion on the median line or from an incomplete reabsorption of the septum originated from their fusion.

Prevalence has been estimated between $16 \%$ and $10 \%$ $[1,2]$, while incidence involves $1 \%$ of general population and $3 \%$ of women having multiple abortions or infertility [2].

The discovery of a genital organ malformation may be random, but these patients show a wide span of symptoms, such as sterility, primary amenorrhea, multiple

\footnotetext{
* Correspondence: felice.sorrentino.1983@gmail.com;

felice.sorrentino@unifg.it

${ }^{1}$ Department of Medical and Surgical Sciences, Institute of Obstetrics and Gynecology, University of Foggia, Viale L. Pinto, 71100 Foggia, Italy Full list of author information is available at the end of the article
}

abortions, severe dysmenorrhea, abdominal pain, and dyspareunia.

One third of anomalies are characterized by septate uterus, one third by bicornuate uterus, $10 \%$ by arcuate uterus, a $10 \%$ by didelphys and unicornuate uterus, and less than $5 \%$ by uterine aplasia according to the American Fertility Society Classification [3].

The most commonly used classifications of Mullerian anomalies in clinical practice include the American Fertility Society Classification and the ESHRE-ESGE Classification developed in 2013 [4, 5]. Nowadays, MDA are diagnosed by non-invasive techniques such as magnetic resonance or 3D transvaginal ultrasound (3D-TV US) [6]. 3D-TV US allows the creation of three-dimensional images useful to study the uterine surface and the cavity and to calculate endometrial volume. In particular, rotational measurement of volume has become possible thanks to the 
introduction of virtual organ computer-aided analysis $\left(V O C A L^{a}\right)$, which is an extension of 3D-VIEW ${ }^{a}$ software (Kretz Technik, Zipf, Austria). Using this new imaging program, the dataset can be rotated around a fixed axis through a number of rotation steps determined by the observer. There are four rotation angles to choose from: $30^{\circ}$, $15^{\circ}, 9^{\circ}$, and $6^{\circ}$, and because the entire dataset is rotated about $180^{\circ}$, it results that we can observe respectively 6,12 , 20 , and 30 planes.

3D-TV US and magnetic resonance are the gold standard for the diagnosis of MDA, but ultrasound is the more cost-effective technique [7].

The most common MDA is the septate uterus, V-a type according to the American Fertility Society classifications and U2b class according to the ESHRE-ESGE classification. These septa are usually repaired by performing a metroplasty with various hysteroscopic techniques. Today hysteroscopic metroplasty is considered the first therapeutic option for septate uterus because it offers several advantages: reduced hospitalization, decreased intra- and post-surgical morbidity, less surgical pelvic adhesions risk, and increased amount of vaginal deliveries [8]. Several tools have been successfully used for hysteroscopic metroplasty: scissor, forceps, operative hysteroscopy, unipolar or bipolar cauterization, laser energy [9-15], but no RCTs have shown that a technique is better than another $[6,16]$. The aim of our study was to evaluate the efficacy of hysteroscopic office technique using a diode laser and its efficacy to increase endometrial volume by comparing transvaginal 3D ultrasound endometrial volume of patients affected by septate uterus before and 3 months after metroplasty.

\section{Materials and methods}

This pilot study was performed and conducted in compliance with the Helsinki Declaration. Informed consent was obtained from all the patients included in the study. We recruited 10 women diagnosed with primary infertility and septate uterus in the Endoscopic Centres of the Universities of Cagliari and Foggia between February and November 2019. Exclusion criteria included infertility due to other explained factors.

\section{Ultrasound evaluation}

All the patients underwent transvaginal 3D ultrasound (GE VolusonTM E10) to evaluate uterine morphology 1 week after ovulation in a controlled spontaneous menstrual cycle (without any hormonal administration). For each women, 3D-TV US was used to evaluate the type of MDA and to calculate pre-surgical endometrial volume (Fig. 1). Women recruited presented a uterus belonging to $\mathrm{V}$ series or to U2 class according to ASRM guidelines and ESHRE-ESGE classification. Endometrial volume was computed by virtual organ computer-aided analysis $\left(\mathrm{VOCAL}^{\mathrm{m}}\right)$ (Figs. 2 and 3).

\section{Surgical technique}

In order to prepare the patients for the surgical procedure Desogestrel $75 \mathrm{mcg}$ was administered at least 1 month before surgery and discontinued directly after the procedure. The patients were placed in a dorsal lithotomy position and a 4-mm continuous-flow office hysteroscope (Bettocchi Office Hysteroscope "size 4" Karl Storz, Tuttlingen, Germany) with a $2.9-\mathrm{mm}$ rod lens optic was introduced into the cervical canal using the vaginoscopic approach, with no speculum and

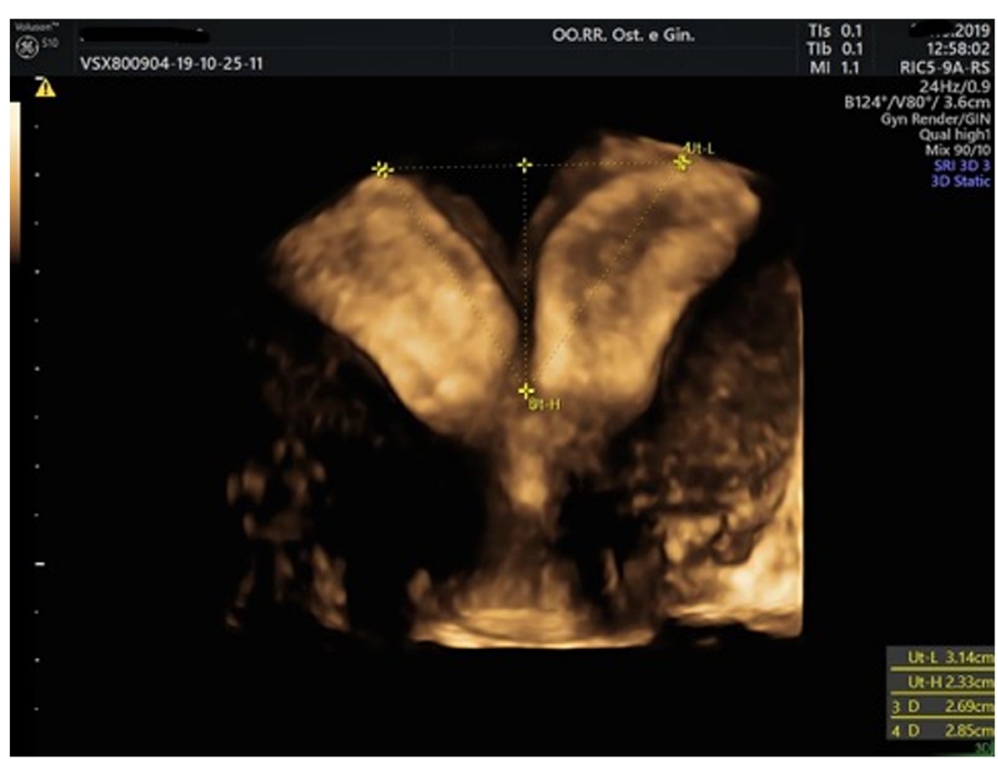

Fig. 1 Preoperatory US evaluation 


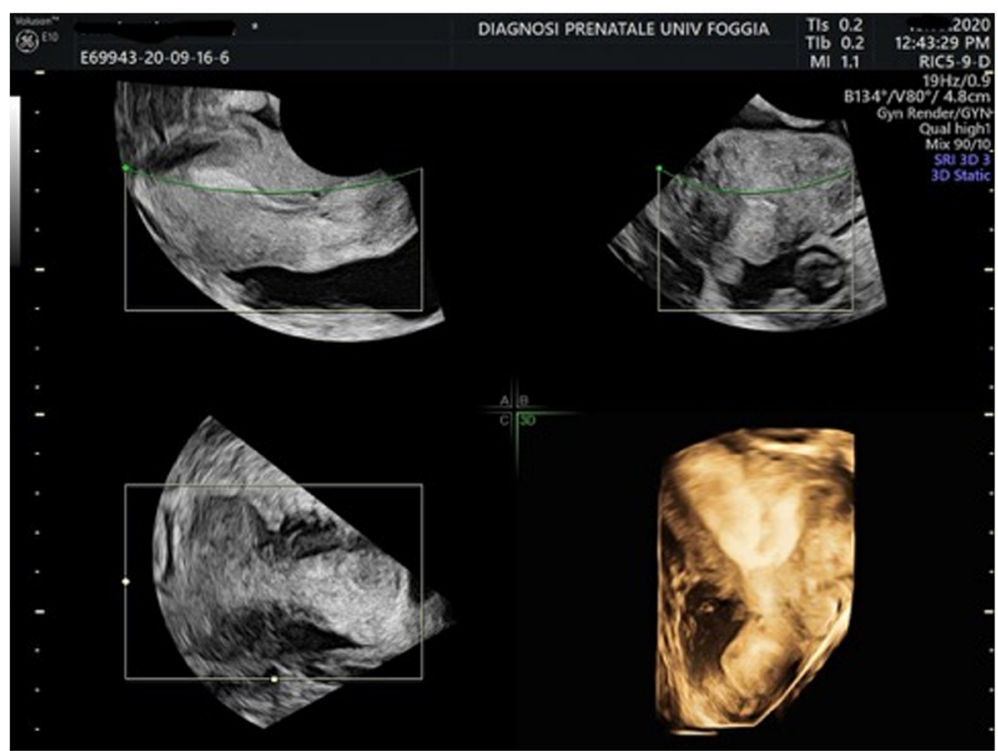

Fig. 2 Post-operatory US evaluation

tenaculum, in an office setting, with no anesthesia and sedation $[17,18]$. We used a new Dual wavelengths Laser System (Leonardo ${ }^{\circ}$, Biolitec ${ }^{\circ}$ DUAL 45). This highly compact diode laser features the combination of two wavelengths, $980 \mathrm{~nm}$ and $1470 \mathrm{~nm}$, giving a contemporary absorption in $\mathrm{H}_{2} \mathrm{O}$ and in hemoglobin $(\mathrm{Hb})$ with excellent ability of hemostasis, cutting and vaporization, as previously shown in hysteroscopic surgery [11-13]. Metroplasty was performed introducing a conical angled fiber (Myofiber CA, IC) with a wider cutting surface through a 5-Fr operative channel (Figs. 4 and 5).
Power laser energy was set at $15 \mathrm{~W}$ maximum vaporization effect.

Uterine cavity distention was obtained using normal saline solution and the pressure was adapted to each patient achieving the maximum distention point with minimal discomfort. The surgical procedure consisted in the complete vaporization and removal of the septum starting from the apex. After cutting and opening the septum with laser vaporization, the procedure was completed by removing residual parts of the septum on the anterior and posterior uterine walls. Histological samples were collected and sent to pathologist. Office hysteroscopic

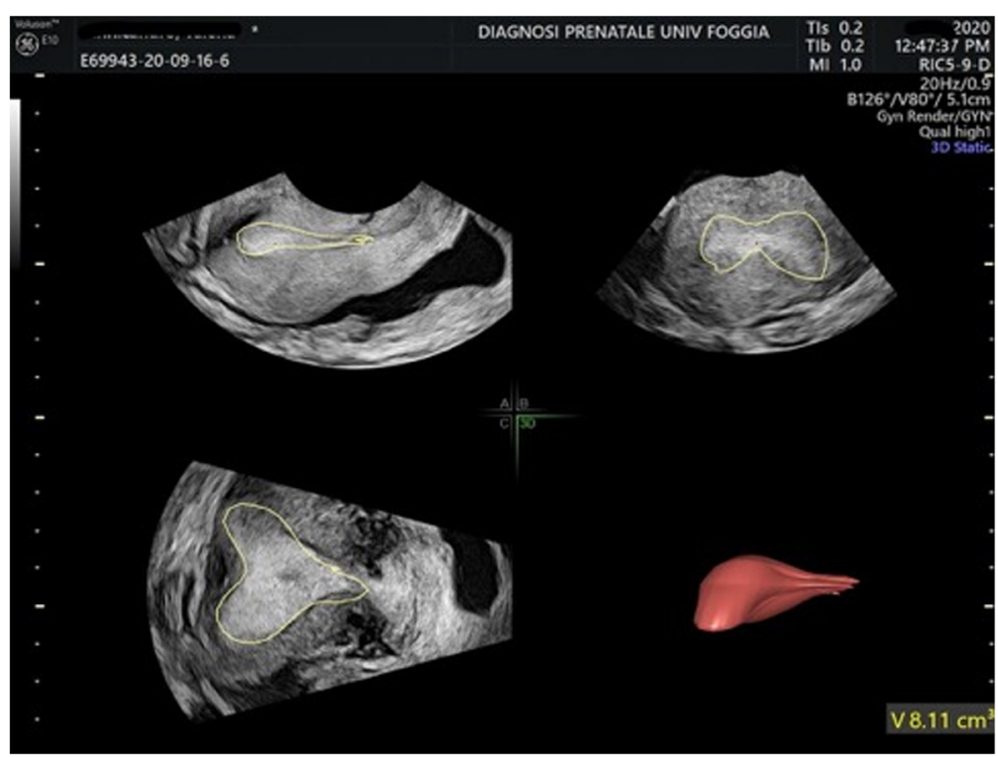

Fig. 3 Example of uterus 3D model in multiplanar display developed by VOCAL-imaging program 


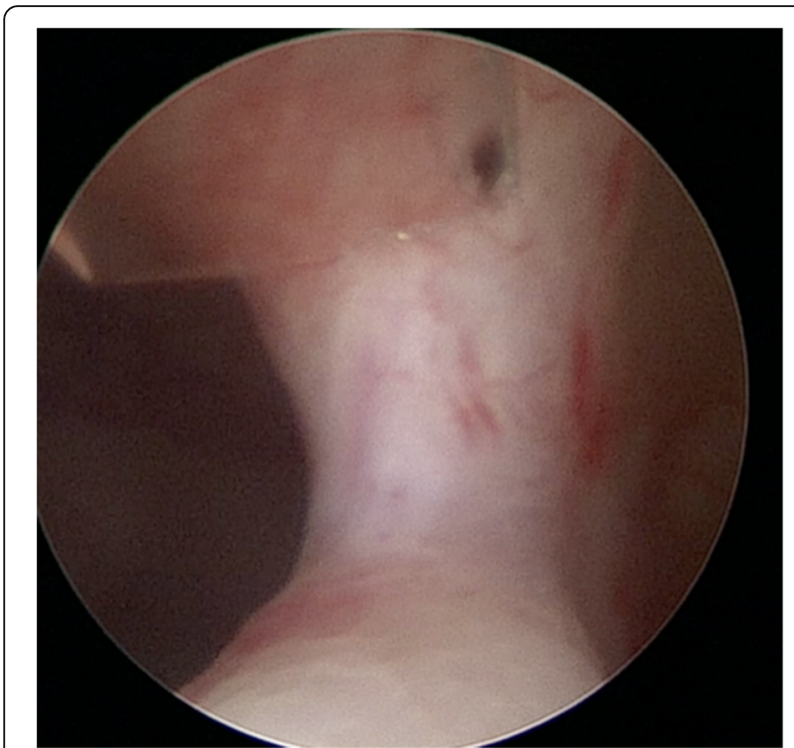

Fig. 4 Hysteroscopic view of metroplasty with laser fiber

follow-up was performed after 3 months in order to evaluate the success of the procedure (residual septa, presence of adhesions). Additionally, in order to assess the uterine morphology and measure the endometrial volume after the procedure, 3D TV-US was performed in luteal phase, 1 week after ovulation in a controlled spontaneous menstrual cycle (after at least two regular spontaneous menstrual cycles). Regular outpatients follow-up was planned every 6 months in order to evaluate the patients regarding their infertility.

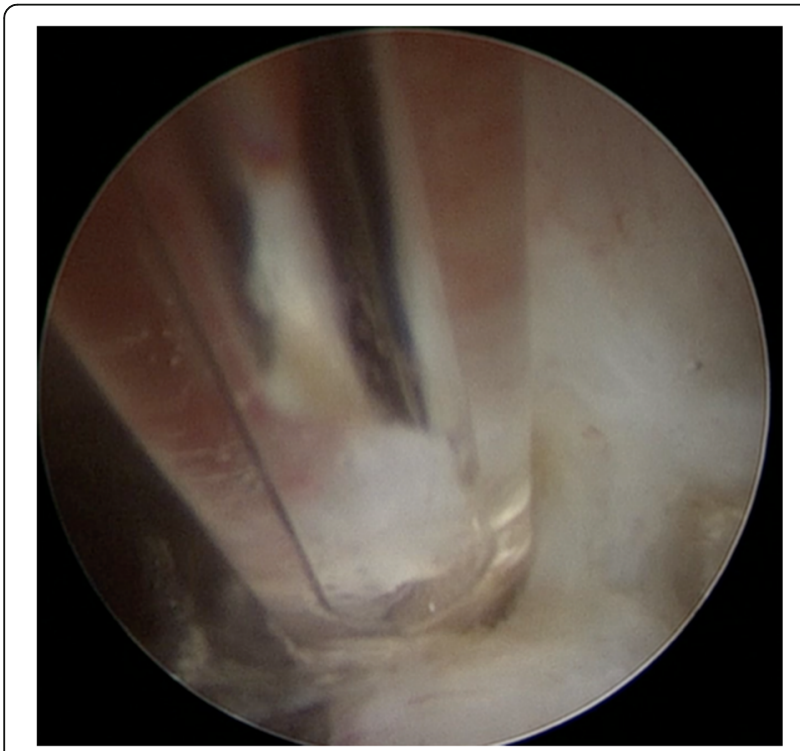

Fig. 5 Hysteroscopic view of metroplasty with laser fiber

\section{Statistical analysis}

For descriptive statistics, continuous variables are reported as median and interquartile range and tested by the Mann-Whitney U test, whereas categorical variables are reported as rates and tested by Fisher's exact test or the chi-square test, as appropriate. Statistical analyses were performed using Stata-SE 14 (StataCorp LP, College Station, TX, USA). All tests were 2 -sided with a significance level set at $p<0.05$.

\section{Results}

Patients' characteristics are summarized in Table 1. The median age was 29.4 years old and the median BMI was $24.2 \mathrm{~kg} / \mathrm{m}^{2}$. All the patients were diagnosed with primary infertility (no other factor was identified as a cause for their infertility). Only one patient experienced a miscarriage at 7 weeks of gestation. The uterine morphology assessed by 3D-TV US revealed a MDA $\mathrm{U} 2 \mathrm{a}$ in 9 patients and $\mathrm{U} 2 \mathrm{~b}$ in 1 patient according to the ESHRE-ESGE classification. The surgical procedure was successful in all patients. There were no early complications and the patients were discharged the same day of the procedure with no discomfort or pain. The pathological examination of the septa removed during the procedure revealed the presence of smooth muscle tissue (leiomyoma). 3D-TV US endometrial volume before and 3 months after metroplasty is shown in Table 2 .

Median endometrial volume was significantly lower preoperatively [4.4 (range $2.5-5.5$ ) vs 6.5 (range 4.4-7.6) $\mathrm{cm}^{3}, \mathrm{p}$ 0.019] and the median increase before and after surgery was $1.9 \mathrm{~cm}^{3}$ (range 1.7-2.1) (Table 3). At the moment of the current study, a 12-month follow-up has been performed in all the patients. None of the patients has reported adverse effect, and one patient is currently spontaneously pregnant 9 months after the surgical procedure.

\section{Discussion}

Mullerian ducts anomalies (MDA) have been historically connected to bad obstetric prognosis characterized by a recurrent miscarriage, preterm delivery, abnormal fetal presentation and fetal or perinatal complications [3]. There are several techniques available for uterine

Table 1 Patients' data

\begin{tabular}{ll}
\hline Age, median (IQR) & $29.4(25.5-33.2)$ \\
BMI, median (IQR) & $24.2(21.1-27.0)$ \\
Infertility, n (\%) & $10(100 \%)$ \\
Previous miscarriages, n (\%) & $1(10 \%)$ \\
Type of Mullerian ducts anomaly (\% of patients) & \\
U2a & $9(90 \%)$ \\
U2b & $1(10 \%)$ \\
\hline
\end{tabular}


Table 2 Evaluation of endometrial volume $\mathrm{cm}^{3}$

\begin{tabular}{ll}
\hline Before surgery $\left(\mathbf{c m}^{\mathbf{3}}\right)$ & After surgery $\left(\mathbf{c m}^{\mathbf{3}}\right)$ \\
\hline 3.8710 & 5.7045 \\
5.5637 & 7.6092 \\
1.7434 & 3.4197 \\
5.0613 & 7.1302 \\
2.1673 & 3.8860 \\
2.4865 & 4.3823 \\
5.9094 & 7.6436 \\
3.8898 & 5.9587 \\
5.4599 & 7.6859 \\
4.8360 & 6.9996 \\
\hline
\end{tabular}

malformations evaluation, office hysteroscopy is particularly useful to evaluate uterine cavity, while transvaginal ultrasound with 3D technique and the use of contrast can evaluate the uterine external morphology, the cavity and the tubes [6]. Ultrasound is easily reproducible and less expensive than magnetic resonance and it can be considered as the gold standard. The development of both the hysteroscopic technique in an outpatient setting and the 3D ultrasound, has increased the knowledge on MDA and has allowed development of new strategies in the treatment of MDA. The calculation of endometrial volume has not been previously studied as a diagnostic factor able to evaluate the success of the hysteroscopic procedure, but can easily and objectively measure the increase in the volume after removing the septa. According to ASRM guidelines, there are no sufficient proofs to recommend any specific method for hysteroscopic septum removal, and there are no randomized studies that showed which surgical technique can be preferred to improve the outcomes [6, 19]. However, some studies have shown that the metroplasty can improve the pregnancy outcomes in women with a history of infertility and miscarriages [20]. Our surgical technique consists in the surgical removal of the septum, and not in the simple opening of the septum as the traditional technique. These techniques have already shown good clinical outcomes in our previous experience with laser [12, 21]. In addition, recently, Haimovich et al. confirmed our preliminary results on hysteroscopic metroplasty with a diode laser. Tissue vaporization and coagulation with low power diode laser energy allow the

Table 3 Endometrial volume values

\begin{tabular}{lll}
\hline $\begin{array}{l}\text { Preoperative median } \\
\text { endometrial volume }\end{array}$ & $\begin{array}{l}\text { Postoperative median } \\
\text { endometrial volume } \\
6.4(2.5,5.5)\end{array}$ & $P .5019$ \\
$\begin{array}{l}\text { Median endometrial } \\
\text { volume increase after } \\
\text { surgery }\end{array}$ & $1.9(1.7,2.1)$ \\
\hline
\end{tabular}

quick elimination of the uterine septum without affecting the underlying myometrium [22]. The septum should be considered as a solid foreign body in the uterine cavity, surrounded by healthy myometrium, as confirmed in the most recent literature [23]. Because of its anatomopathological nature of leiomuscular tissue, a septum should be potentially treated as a myoma. In conclusion, diode laser is a feasible and safe alternative to the scissor, bipolar twizzle, and bipolar or monopolar resectoscope techniques. It allows the vaporization of the uterine septum demonstrating extreme precision of cutting, precise control of tissue vaporization, controlled power of penetration, a high capacity of hemostasis, the absence of electrical interferences, high safety, and good compliance of patients due to office setting without the need for cervical dilatation [24-26]. Among the limitations of our study we can include the relatively small number of the sample and the lack of a control group. A potential side effect of our technique could be the weakening of the uterine walls because of the removal of the septum, that might potentially have a negative effect on the pregnancy and a spontaneous delivery; therefore, further larger randomized studies are necessary to correlate our positive first clinical data to obstetric outcomes.

\section{Conclusions}

Office hysteroscopic metroplasty for septate uterus with diode laser confirms to be a feasible and safe alternative to other available techniques and it could increase endometrial volume after the procedure. A randomized clinical study is currently ongoing at our department in order to better evaluate the laser metroplasty technique and to assess if the increase in endometrial volume by 3D-TV US can be used as a prognostic factor for the reproductive outcomes.

\section{Acknowledgements}

Not applicable.

\section{Authors' contributions}

Conceptualization, L.N. and F.S.; writing-original draft, F.S., L.N. and V. D. F.; writing-review and editing, F.S., S.A., M.B., M.F.; supervision, L.N. and S.A. All authors have read and agreed to the published version of the manuscript.

Funding

No funding was sought for the purpose of this study.

Availability of data and materials

All data generated or analyzed during this study are included in this published article.

\section{Declarations}

Ethics approval and consent to participate

The study was approved by the Ethical Committee of both institutions (Foggia and Cagliari) and performed in compliance with the Helsinki Declaration. Informed consent was obtained from all the patients included in the study.

Consent for publication

Patients signed informed consent regarding publishing their data. 


\section{Competing interests}

The authors report no conflicts of interest in this work.

\section{Author details}

'Department of Medical and Surgical Sciences, Institute of Obstetrics and Gynecology, University of Foggia, Viale L. Pinto, 71100 Foggia, Italy. 2Department of Surgical Sciences, Division of Gynecology and Obstetrics, University of Cagliari, Cagliari, Italy.

Received: 5 November 2020 Accepted: 18 May 2021

Published online: 01 June 2021

\section{References}

1. Olpin JD, Heilbrun M (2009) Imaging of Müllerian duct anomalies. Clin Obstet Gynecol 52:40-56. https://doi.org/10.1097/GRF.0b013e3181958439

2. Troiano RN, McCarthy SM (2004) Mullerian duct anomalies: imaging and clinical issues. Radiology 233:19-34. https://doi.org/10.1148/ra diol.2331020777

3. Lewis AD, Levine D (2010) Pregnancy complications in women with uterine duplication abnormalities. Ultrasound Q 26:193-200. https://doi.org/10.1097/ RUQ.0b013e3181efa745

4. Buttram VC Jr, Gomel V, Siegler A, De Cherney A, Gibbons W, March C (1988) The American Fertility Society classifications of adnexal adhesions, distal tubal occlusion, tubal occlusion secondary to tubal ligation, tubal pregnancies, Mullerian anomalies and intrauterine adhesions. Fertil Steril 49: 944-955. https://doi.org/10.1016/S0015-0282(16)59942-7

5. Grimbizis GF, Gordts S, Di Spiezio SA et al (2013) The ESHRE/ESGE consensus on the classification of female genital tract congenital anomalies. Hum Reprod 28:2032-2044. https://doi.org/10.1093/humrep/det098

6. Practice Committee of the American Society for Reproductive Medicine (2016) Uterine septum: a guideline. Fertil Steril 106:530-540. https://doi. org/10.1016/j.fertnstert.2016.05.014

7. Bermejo C, Martínez Ten P, Cantarero R et al (2010) Three-dimensional ultrasound in the diagnosis of Müllerian duct anomalies and concordance with magnetic resonance imaging. Ultrasound Obstet Gynecol 35:593-601. https://doi.org/10.1002/uog.7551

8. Perino A, Mencaglia L, Hamou J, Cittadini E (1987) Hysteroscopy for metroplasty of uterine septa: report of 24 cases. Fertil Steril 48:321-323. https://doi.org/10.1016/s0015-0282(16)59364-9

9. Donnez J, Nisolle M (1997) Endoscopic laser treatment of uterine malformations. Hum Reprod 12:1381-1387. https://doi.org/10.1093/ oxfordjournals.humrep.a019590

10. Daniell JF (1984) The role of lasers in infertility surgery. Fertil Steril. 42:815823. https://doi.org/10.1016/s0015-0282(16)48249-x

11. Nappi L, Sorrentino F, Angioni S, Pontis A, Greco P (2016) The use of laser in hysteroscopic surgery. Minerva Ginecol 68:722-726

12. Nappi L, Pontis A, Sorrentino F, Greco P, Angioni S (2016) Hysteroscopic metroplasty for the septate uterus with diode laser: a pilot study. Eur Obstet Gynecol Reprod Biol 206:32-35. https://doi.org/10.1016/j.ejogrb.2016. 08.035

13. Nappi L, Sorrentino F, Angioni S et al (2017) Feasibility of hysteroscopic endometrial polypectomy using a new dual wavelengths laser system (DWLS): preliminary results of a pilot study. Arch Gynecol Obstet 295:3-7. https://doi.org/10.1007/s00404-016-4232-5

14. Heinz-Peer G (2007) Evaluation of infertility. In: Hamm B, Forstner R (eds) MRI and CT of the female pelvis. Medical Radiology (Diagnostic Imaging). Springer, Berlin, Heidelberg. https://doi.org/10.1007/978-3-540-68212-7_16

15. Daniilidis A, Kalpatsanidis A, Kalkan U, Kasmas S, Pados G, Angioni S (2020) Reproductive outcome after operative hysteroscopy for uterine septum: scissors or diathermy? Minerva Ginecol 72:36-42. https://doi.org/10.23736/ S0026-4784.20.04444-5

16. National Institute for Health and Care Excellence. Hysteroscopic Metroplasty of A Uterine Septum for Recurrent Miscarriage. Available online: https:// www.nice.org.uk/guidance/ipg510 (Accessed on 23 Jan 2015).

17. Pluchino N, Ninni F, Angioni S et al (2010) Office vaginoscopic hysteroscopy in infertile women: effects of gynecologist experience, instrument size, and distention medium on patient discomfort. J Minim Invasive Gynecol 17:344350. https://doi.org/10.1016/j.jmig.2010.01.015

18. Di Spiezio SA, Bettocchi S, Spinelli M et al (2010) Review of new officebased hysteroscopic procedures 2003-2009. J Minim Invasive Gynecol 17: 436-448. https://doi.org/10.1016/j.jmig.2010.03.014
19. Loddo A, D'Alterio MN, Neri M, Masala F, Lo Cane F, Melis GB (2017) Pregnancy complications after hysteroscopic metroplasty: a ten-year casecontrol study. Surg Technol Int 30:205-209

20. Pabuçcu R, Gomel V (2004) Reproductive outcome after hysteroscopic metroplasty in women with septate uterus and otherwise unexplained infertility. Fertil Steril 8:1675-1678. https://doi.org/10.1016/j.fertnstert.2 003.10 .035

21. Bettocchi S, Ceci O, Nappi L, Pontrelli G, Pinto L, Vicino M (2007) Office hysteroscopic metroplasty: three "diagnostic criteria" to differentiate between septate and bicornuate uteri. J Minim Invasive Gynecol 14:324328. https://doi.org/10.1016/j.jmig.2006.11.010

22. Esteban Manchado B, Lopez-Yarto M, Fernandez-Parra J, Rodriguez-Oliver A, Gonzalez-Paredes A, Laganà AS, Garzon S, Haimovich S (2020) Office hysteroscopic metroplasty with diode laser for septate uterus: a multicenter cohort study. Minim Invasive Ther Allied Technol 22:1-7. https://doi.org/10.1 080/13645706.2020.1837181

23. Fascilla FD, Resta L, Cannone R et al (2020) Resectoscopic metroplasty with uterine septum excision: a histologic analysis of the uterine septum. J Minim Invasive Gynecol 27:1287-1294. https://doi.org/10.1016/ j.jmig.2019.11.019

24. Abis P, Bigozzi MA, Dotto J et al (2020) Pain Management During Office Hysteroscopy: A Survey of Hysteroscopists. Surg Technol Int 37:161-166

25. Sorrentino F, Petito A, Angioni S et al (2021) Impact of anxiety levels on the perception of pain in patients undergoing office hysteroscopy. Arch Gynecol Obstet 303:999-1007. https://doi.org/10.1007/s00404-020-05885-9

26. Danilidis A, Pantelis A, Dinas K et al (2012) Indications of diagnostic hysteroscopy, a brief review of the literature. Gynecol Surg 9:23-28. https:// doi.org/10.1007/s10397-011-0695-3

\section{Publisher's Note}

Springer Nature remains neutral with regard to jurisdictional claims in published maps and institutional affiliations.

\section{Submit your manuscript to a SpringerOpen ${ }^{\circ}$ journal and benefit from:}

- Convenient online submission

Rigorous peer review

- Open access: articles freely available online

High visibility within the field

- Retaining the copyright to your article

Submit your next manuscript at $\boldsymbol{\nabla}$ springeropen.com 